\section{Forestry in New Zealand}

THE annual report of the State Forestry Service of New Zealand, drawn up by Mr. Alex. R. Entrican, director of forestry, is a concise document dealing with various forest activities. The great value of the report lies in the attention it directs to the position of the very large area of exotic plantations existing in the country and the difficulties facing their treatment. "A timber famine scare", says the author, "in all English-speaking countries was one of the products of the Great War, and it was perhaps inevitable that under the existing conditions of those times extensive tree-planting with quick-growing exotics should follow. Employment was required for large numbers of repatriated soldiers ; then mass-production psychology, born out of munitions and automobile manufacture, favoured large-scale forestry operations. To some degree extensive areas had been planted with unsuitable species or consist of soil fit for neither agriculture nor forestry. The former has often been due to the impossibility of obtaining the amounts of suitable seed required in the general large scramble to plant."

The most serious result, however, is connected with neither of the above. This urgent large-scale planting has been the creation of 750,000 acres of plantations with complete disregard for the essential necessity of creating well-distributed age classes. For example, three State exotic forests totalling 41,000 acres were 91 per cent planted during the five-year period 1927-31. During the same period more than 80 per cent of the total State insignis pine stands were planted, and more than 50 per cent of the privately owned stands. It will be obvious to any forester that the correct management of this enormous area of almost even-aged forests is going to prove a difficult problem. As the director of forestry correctly says, only by intensive planning and organization may enormous losses be avoided in these medium-age classes which form such a large proportion of the exotic forest resource. A future better distribution of age classes is obviously an aim. To assist, a recommendation is made that for the present all fellings in indigenous forests should cease.

\section{"Kill Statistics" from California}

GAME birds and animals form a valuable food resource of any country, but the permanent value of the resource depends upon the skill with which it is at once utilized and husbanded. In California the control of game is supervised by the Division of Fish and Game, and in order that effective regulations may be made it is essential that the Division should know how many individuals of each species are killed in the various parts of the State. In one area a species may be abundant in spite of the sportsman, in another it may require further protection. The method of collecting the information upon which legislation depends is by questionnaire, attached to hunting licence application forms, and the experts are convinced that the returns give a reasonably accurate tale of the slaughter. The statistics for 1938 have been published by J. I. Hunter and
Donald H. Fry, jun. and reveal some astonishing numbers (California Fish and Game, 26, 310; 1940). The estimated number of ducks killed was 950,000 ; geese, 90,000; pigeons (Columba), 95,000; doves (mainly Zenaidura), 1,700,000; quail, 1,500,000; pheasants, 125,000. The mammal numbers are also very considerable: cottontail and brush rabbits, 500,000 ; jack rabbits, 750,000 ; deer (two species), 35,045 . In $1939,43,251$ deer were killed, a number strongly in contrast with the moderate slaughter of twenty-five years ago, when the estimate of killed reached only 12,000 .

\section{Caffelite: a New Plastic}

For many years excess production of coffee has been a serious problem for the Brazilian Government; thousands of bags have been deliberately destroyed every year to prevent them coming on the market. Now that markets in Germany, Italy and other European countries are lost to them, the position is even more serious. According to the Electrician of April 18, an investigation conducted in New York has led to the discovery of a new plastic material, which is known as 'Caffelite', and industrial plants will come into operation in Brazil this year in which at least part of the excess supply of coffee will be absorbed in the manufacture of Caffelite. The product is said to have useful electric properties at low frequencies. The material is moulded under pressure of one or two tons per square inch, and has a specific gravity of $1 \cdot 43$, that is, about ten per cent higher than wood flour filled phenolic moulding materials of the 'Bakelite' type. The other physical properties are stated to be similar to those of 'Bakelite', and it is claimed that all colours can be produced except white.

\section{Engineering Construction in India}

IN Engineering of April 4 there is an article on a welded water main in Burma which gives an interesting illustration of the growing self-sufficiency of India and Burma from the point of view of engineering construction. Forty-three miles of water main $4 \mathrm{ft} .10 \mathrm{in}$. in diameter were required for the city of Rangoon. The steel plate was rolled by the Tata Iron and Steel Co. Ltd. at Jamshedpur, and shipped to Rangoon, where the fabrication was effected by Messrs. Braithwaite, Burn and Jessop Construction, Ltd. The main was made in lengths of $25 \mathrm{ft}$., each length of pipe consisting of three plates in the circumference, the plates as rolled being $62 \mathrm{in}$. wide by $\frac{7}{16}$ in. thick. After the plates had been bent to onethird of a circle, each set of three was assembled in six rigid rings spaced equally along the length of the pipe and supported on rollers. An automatic carbonarc welding head, of the 'electronic tornado' type, mounted on a small carriage, was then run along the longitudinal seam at the bottom of the assembly and the pipe rotated for the welding of the two remaining seams in the same position. The inside seams were butt-welded. They were not completely welded from the inside only, a second run on the outside surface of the pipe with an automatic carbon-arc welding- 